\title{
Excited Carrier Dynamics in a Dye-Sensitized Niobate Nanosheet Photocatalyst for Visible-Light Hydrogen Evolution
}

Shunta Nishioka, ${ }^{1}$ Takayoshi Oshima, ${ }^{2, \#}$ Shota Hirai, ${ }^{2}$ Daiki Saito, ${ }^{2}$ Koya Hojo, ${ }^{2}$ Thomas E. Mallouk, ${ }^{* 1}$ Kazuhiko Maeda*2

${ }^{1}$ Department of Chemistry, University of Pennsylvania, 231 S. 34th Street Philadelphia, PA 19104, United States

${ }^{2}$ Department of Chemistry, School of Science, Tokyo Institute of Technology, 2-12-1-NE-2 Ookayama, Meguroku, Tokyo 152-8550, Japan

*To whom corresponding authors should be addressed.

T.E.M.: mallouk@sas.upenn.edu; K.M.: maedak@chem.titech.ac.jp 


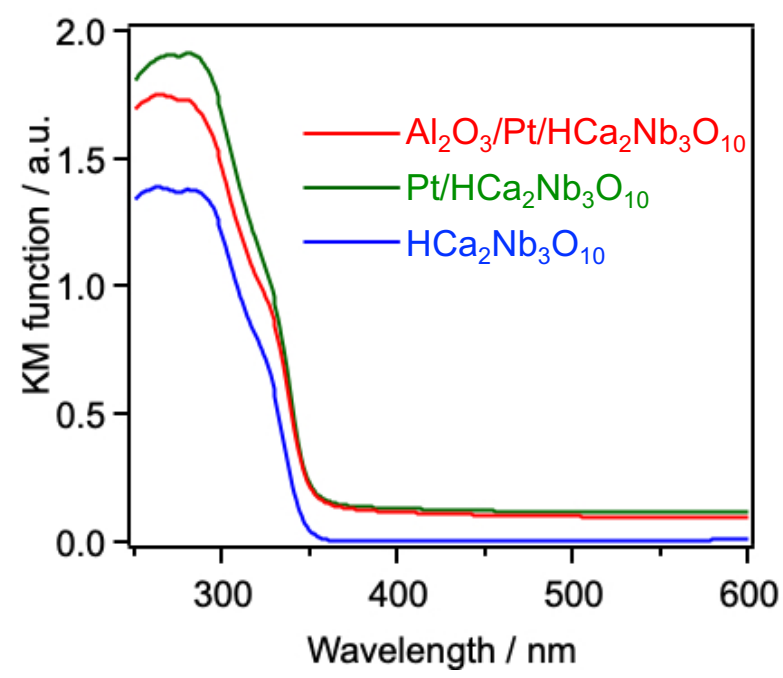

Figure S1. UV-visible diffuse reflectance spectra of $\mathrm{HCa}_{2} \mathrm{Nb}_{3} \mathrm{O}_{10}$ nanosheets with various modifications.

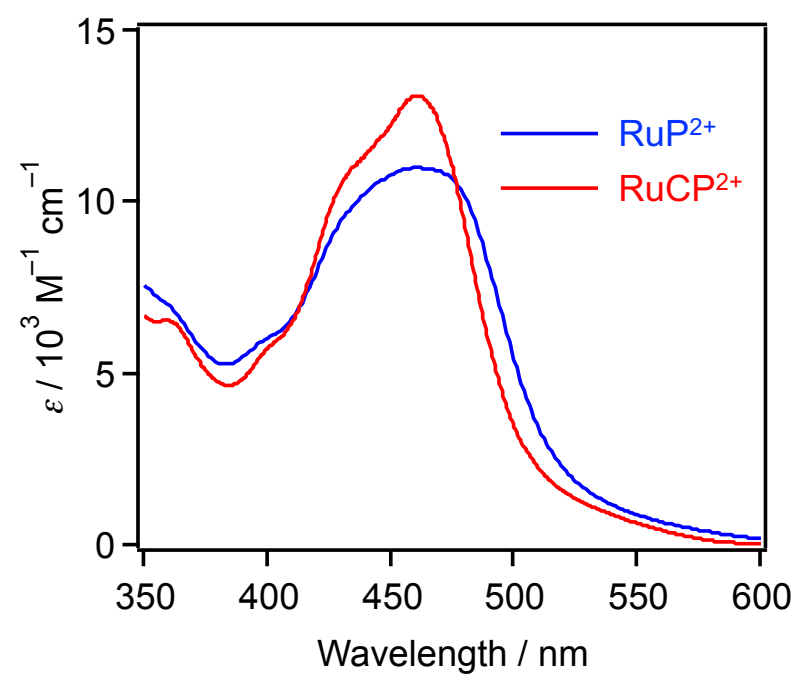

Figure S2. UV-visible absorption spectra of $\mathbf{R u} \mathbf{P}^{2+}$ in $\mathrm{H}_{2} \mathrm{O}$ and of $\mathbf{R u C P} \mathbf{P}^{2+}$ in $\mathrm{CH}_{3} \mathrm{CN}$. 

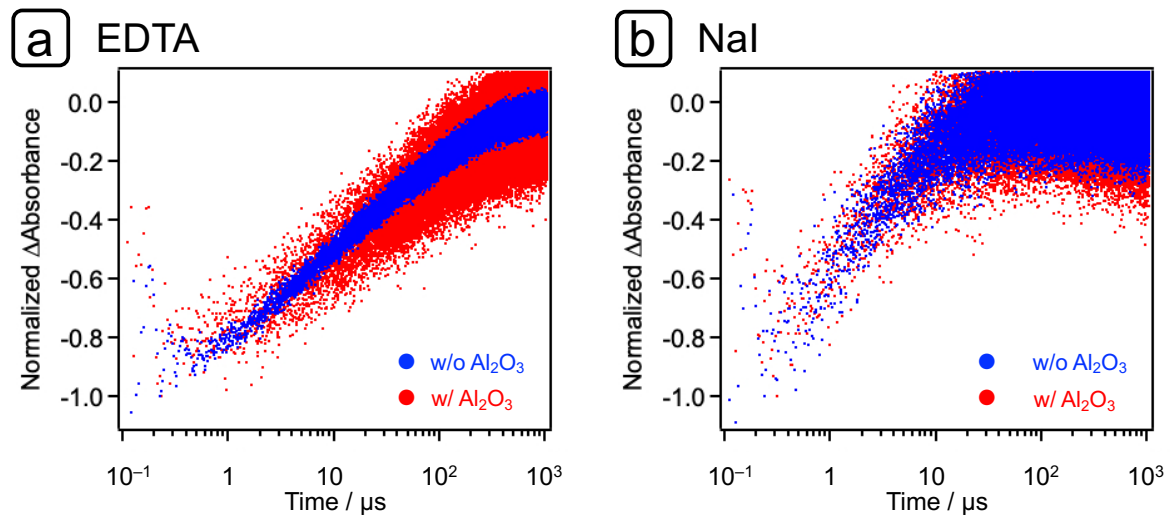

Figure S3. Time-dependent absorbance change in transient absorption measurements of $\mathbf{R u} \mathbf{P}^{\mathbf{2 +}}-$ sensitized $\mathrm{Pt} / \mathrm{HCa}_{2} \mathrm{Nb}_{3} \mathrm{O}_{10}$ nanosheets with and without $\mathrm{Al}_{2} \mathrm{O}_{3}$ suspended in aqueous (a) EDTA and (b) NaI solutions. Measurement conditions: solution, aqueous EDTA solution $(10 \mathrm{mM}, \mathrm{pH}=4.0)$ or aqueous NaI solution (10 mM, $\mathrm{pH}=3.9)$; monitoring wavelength: $475 \mathrm{~nm}$.

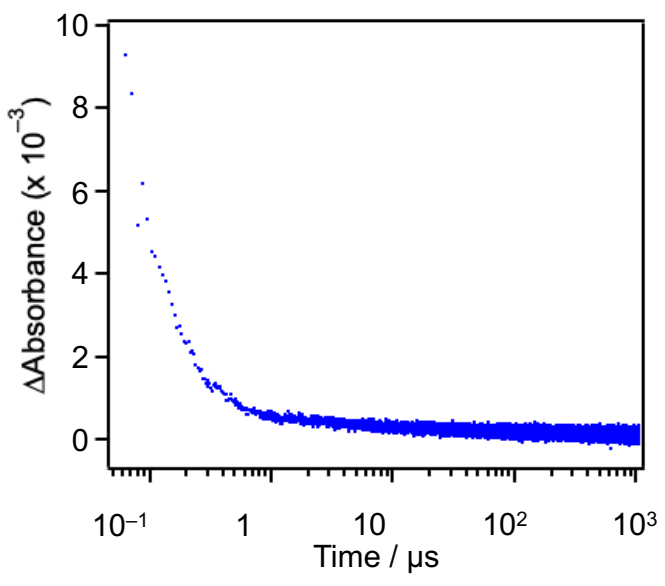

Figure S4. Time-dependent absorbance change in transient absorption measurements of $\mathbf{R u} \mathbf{P}^{\mathbf{2 +}}-$ sensitized $\mathrm{Pt} / \mathrm{HCa}_{2} \mathrm{Nb}_{3} \mathrm{O}_{10}$ nanosheets suspended in water. Measurement conditions: solution, water ( $\mathrm{pH}$ $=4.0$ ); monitoring wavelength: $700 \mathrm{~nm}$. The emission from $\mathbf{R} \mathbf{u} \mathbf{P}^{2+*}$ was appeared up to $\sim 1 \mu \mathrm{s}$ and the $\Delta$ absorption after the emission would be $\mathbf{R u P}^{\mathbf{3}}$ species. 
Table S1. Absorption Decay Lifetimes of $\mathbf{R u P}^{2+}$ Adsorbed on $\mathrm{Pt} / \mathrm{HCa}_{2} \mathrm{Nb}_{3} \mathrm{O}_{10}$ Nanosheets Suspended in Aqueous NaI Solution

\begin{tabular}{|c|c|c|c|c|}
\hline Entry & $\mathrm{Al}_{2} \mathrm{O}_{3}$ & $\begin{array}{c}\tau_{1} / \mu \mathrm{s} \\
(\%)\end{array}$ & $\begin{array}{c}\tau_{2} / \mu \mathrm{s} \\
(\%)\end{array}$ & $\begin{array}{c}\tau_{3} / \mu \mathrm{s} \\
(\%)\end{array}$ \\
\hline $1^{a}$ & No & $\begin{array}{c}1.4 \pm 0.1 \\
(57.7)\end{array}$ & $\begin{array}{l}9 \pm 1 \\
(42.3)\end{array}$ & - \\
\hline $2^{a}$ & Yes & $\begin{array}{c}1.1 \pm 0.2 \\
(53.5)\end{array}$ & $\begin{array}{l}9 \pm 1 \\
(46.5)\end{array}$ & - \\
\hline $3^{b}$ & No & $\begin{array}{c}1.1 \pm 0.1 \\
(42.6)\end{array}$ & $\begin{array}{c}7.5 \pm 0.8 \\
(37.8)\end{array}$ & $\begin{array}{c}0.01 \pm 0.003 \\
(19.6)\end{array}$ \\
\hline $4^{b}$ & Yes & $\begin{array}{c}1.0 \pm 0.2 \\
(41.4)\end{array}$ & $\begin{array}{c}8 \pm 1 \\
(38.5)\end{array}$ & $\begin{array}{c}0.009 \pm 0.005 \\
(20.1)\end{array}$ \\
\hline
\end{tabular}

${ }^{a}$ Fitting was conducted by using the following double-exponential function:

$$
f(x)=y_{0}+\mathrm{A}_{1} \exp \left(-\frac{x-x_{0}}{\tau_{1}}\right)+\mathrm{A}_{2} \exp \left(-\frac{x-x_{0}}{\tau_{2}}\right),
$$

${ }^{b}$ The same data from entries 3 and 6 in Table 2.
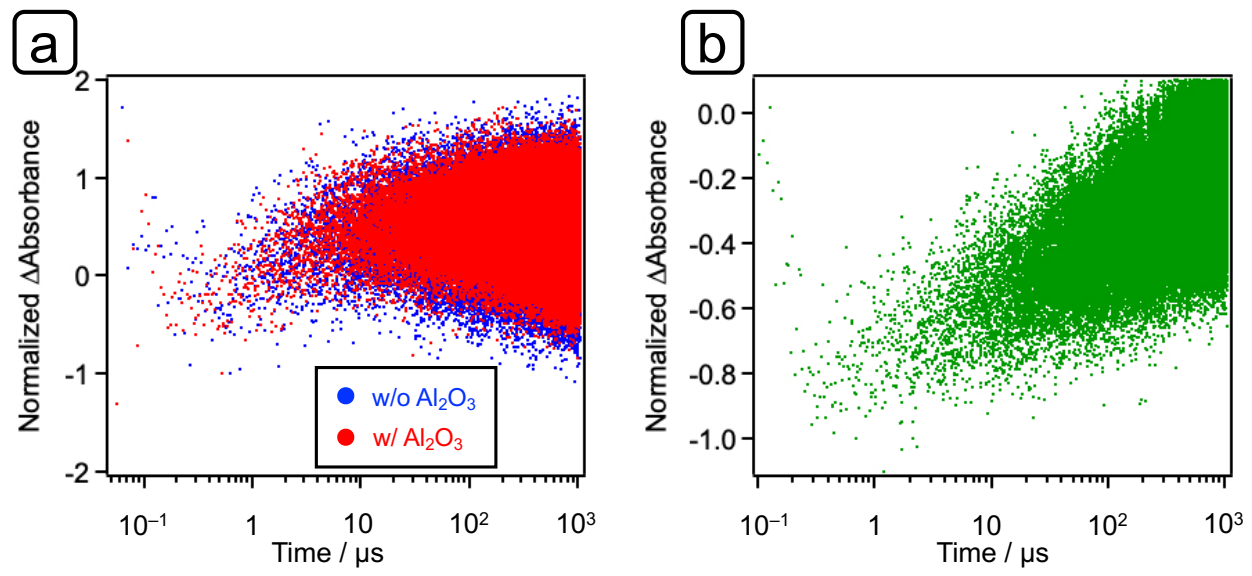

Figure S5. Time-dependent absorbance change in transient absorption spectra of (a) $\mathbf{R u P}^{\mathbf{2 +}}$-sensitized $\mathrm{HCa}_{2} \mathrm{Nb}_{3} \mathrm{O}_{10}$ nanosheets with and without $\mathrm{Al}_{2} \mathrm{O}_{3}$, suspended in aqueous $\mathrm{NaI}$ solutions $(10 \mathrm{mM}, \mathrm{pH}=3.9)$ monitored at $380 \mathrm{~nm}$ and (b) $\mathbf{R u} \mathbf{P}^{2+}$-sensitized $\mathrm{HCa}_{2} \mathrm{Nb}_{3} \mathrm{O}_{10}$ nanosheets without $\mathrm{Al}_{2} \mathrm{O}_{3}$, suspended in water $(\mathrm{pH}=4.0)$ monitored at $380 \mathrm{~nm}$. An initial $\Delta$ absorbance decrease was observed in (a), which is due to bleaching of the $\mathrm{d}$ - $\mathrm{d}$ transition of the $\mathrm{Ru}$ complex. It was confirmed that the kinetics of this absorbance change were similar to those of MLCT bleaching of $\mathbf{R u P} \mathbf{P}^{2+}$ at $475 \mathrm{~nm}$. 